\title{
Summary of Color Difference on Exterior of Stainless Steel Buildings
}

\author{
Zhenglin Luo, Yaoheng Wang, Lin Huang \\ China Construction Shenzhen Decoration Co., Ltd, Shenzhen, China \\ Email address: \\ luozlluozl@qq.com (Zhenglin Luo),378116126@qq.com (Yaoheng Wang)
}

To cite this article:

Zhenglin Luo, Yaoheng Wang, Lin Huang. Summary of Color Difference on Exterior of Stainless Steel Buildings. Engineering and Applied Sciences. Vol. 5, No. 6, 2020, pp. 149-157. doi: 10.11648/j.eas.20200506.16

Received: October 27, 2020; Accepted: November 21, 2020; Published: December 22, 2020

\begin{abstract}
The color of stainless steel surface is mainly determined by its own material or substance attached to the outer face of stainless steel. It can be roughly classified as follows: 1. Color of stainless steel itself or the unique outer surface color after physical processing such as polishing, frosting, drawing and sand blasting. 2. Attach a thin layer of other metals or alloys to the surface of stainless steel object with different chemical electrolysis principles to make stainless steel show specific color and promote the enhancement for corrosion resistance of stainless steel. 3. The outer surface of stainless steel is exposed to the natural environment, the metal (steel component) in contact with the air or natural environment (temperature, air, time, surface roughness, etc.), thus a layer of oxide will be oxidized on its surface, which tends to gradually become the same color. The characteristics of stainless steel include durability, little maintenance required, long service life, and scientific and modern appearance. The curtain wall of Science and Technology Museum of Start of Optics Valley is made of stainless steel, which also avoids light pollution caused by stainless steel surface to the surrounding environment. The architect performed physical sandblasting on exterior to form diffuse reflection on the surface. On the outer surface with countless tiny concave potholes of stainless steel after sandblasting, the change in stainless steel color of building exterior was caused by the change in angle and light of plates. In this regard, the changes in surface color of stainless steel were tried to improve by consulting relevant experts in stainless steel materials and performing a lot of related tests. This article includes detailed records and analyses of the process. Readers may therefore be inspired to avoid or solve similar problems in similar curtain wall with stainless steel surface.
\end{abstract}

Keywords: Curtain Wall with Stainless Steel Surface, Color Difference, Pickling, Natural Oxidation, Dazzling Light Effect

\section{Introduction}

China Architecture Science and Technology Museum of China Construction - Start of Optics Valley is located at the northeast corner of intersection of Gaoxin Avenue and Guanggu $6^{\text {th }}$ Road in Wuhan (hereafter referred to as "Science and Technology Museum".

Science and Technology Museum is presented as a quadrangle courtyard with archaistic ridge and roof, inheriting the essence of traditional Chinese architecture. The building in the shape of "seed and leaf" is located in the middle of the courtyard. The "leaf", made of stainless steel plate and curved glass, grows on the east and west sides of "seed". The seed is made of point-supported hyperbolic arc glass balls. The shape of whole building implies the experience of sowing, rooting, sprouting, growing, flowering and fruiting of China Construction Third Engineering Bureau Co., Ltd., represents hope and growth, and embodies the tenacious vitality of the enterprise, as well as the spiritual strength of continues struggle, that is "be faithful to our original aspiration and continue marching forward".

The overall floorage of China Architecture Science and Technology Museum is $69119 \mathrm{~m}^{2}$ with the curtain wall area of $8308 \mathrm{~m}^{2}$. The peak elevation of the building leaf is $58.128 \mathrm{~m}$, and the low elevation is $-13.800 \mathrm{~m}$ on the third floor underground.

After the project introduction above, the following is a summary of color difference on stainless steel curtain walls of exterior of Science and Technology Museum.

As an external display window, Science and Technology Museum is different from general buildings with unique external facade shape and super large area of stainless steel surface. 


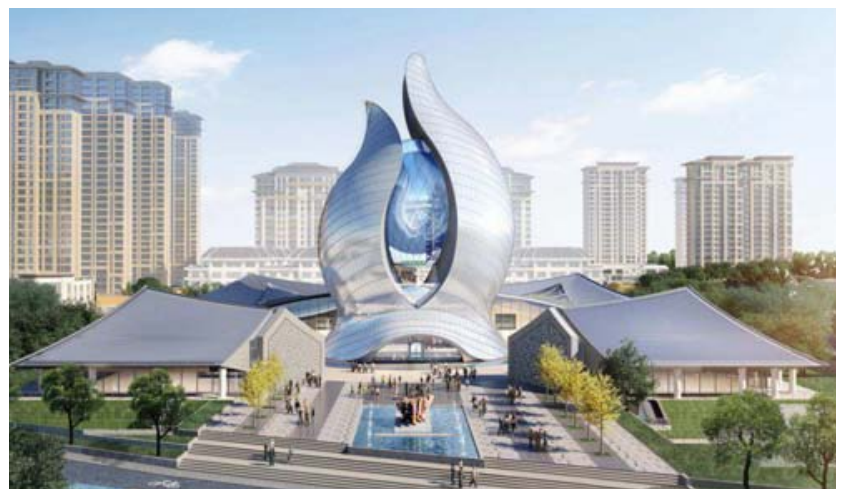

Figure 1. The architectural effect of the project.

The control of stainless steel color difference on exterior of Science and Technology Museum is more or less affected by the material selection of exterior, surface preparation after fixing the material, different installation angles of panel, absorption and reflection of light and other reasons.

\section{Parameters of Stainless Steel Curtain wall Panel of Exterior Are as Follows}

The developer representative, construction organization representative and person in charge of manufacturer witnessed and confirmed the samples of stainless steel for exterior.

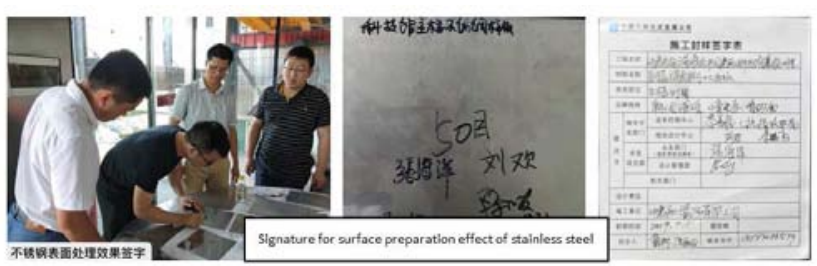

Figure 2. Signature for surface preparation effect of stainless steel.

Table 1. Sample confirmation form.

\begin{tabular}{lll}
\hline No. & Items & Contents \\
\hline 1 & Thickness & $4 \mathrm{~mm}$ thick \\
2 & Material & $316 \mathrm{~L}$ \\
3 & Surface preparation & 50-mesh glass sand \\
4 & Supplier of raw panel & POSCO (The stainless steel produced by 3 furnaces is used due to the large demand for stainless steel) \\
5 & Shape & Hyperbolic panel, each product has different specifications, shapes, sizes and curved surface radian \\
6 & Processing technology & Carry out stiffener welding, assembly and sandblasting with surface preparation, laser cutting, multi-point forming \\
7 & Area & and 3D laser. \\
\hline
\end{tabular}

\section{Discovery of Stainless Steel Color Difference}

According to the on-site modeling and the tight completion schedule of the developer, the Project Department decided to adopt prefabricated installation after meeting discussion. One large stainless steel unit plate was assembled by 5-8 small plates on site and installed from top to bottom according to plate number.

After the installation of the top stainless steel plates of the Science and Technology Museum, color difference between the top stainless steel plates installed around the building was found in the distance. The color changed with different viewing angle. The color difference was also different when observed in the morning and evening, or on sunny, cloudy and rainy days.

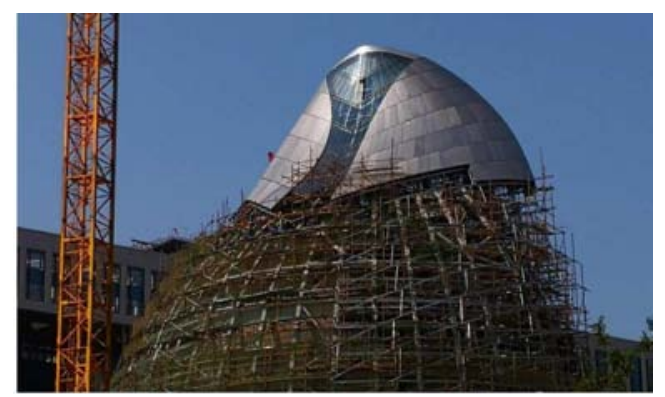

Figure 3. Stainless steel color difference (illuminated face).

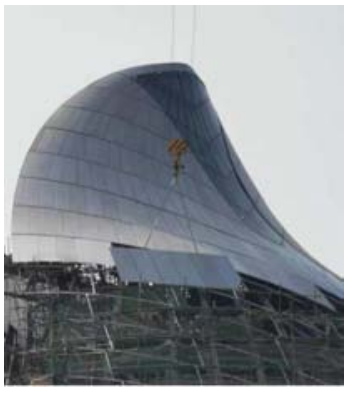

Figure 4. Stainless steel color difference (shady face).

\section{Measures Once Problems Occur}

The on-site installation was suspended immediately; the plate production in processing plate was stopped [1].

The plates sent from the factory to the site have undergone strict quality tests before delivery, including hyperbolic deformation accuracy, comparison of plate appearance with sealed samples, and a series of inspections in product processing [2]. After the occurrence of color difference, the company established a color difference team, sent representatives to inspect plates on site, and went to the processing plant to check the processing of stainless steel panel immediately.

\section{Results of Preliminary Inspection}

Reasons for undiscovered color difference: The brightness 
inside the factory was different from outside, thus it was difficult to find the color difference between plates. It was difficult to find the color difference of plates arranged at the same angle indoors. After placing a plate at multiple angles, un-conspicuous color differences can be seen [3].

A sand lasting machine was added during the period to meet the production needs.

The plates were moved to the outdoor sunlight and arranged at the same angle, which showed color difference or ripple, stripes. The plate was arranged at multiple angles, the color difference was changed with angle, which was more obvious than indoors.

\section{Analysis and Preparation Measures for Color Difference}

For color difference of stainless steel, the Project Department invited experts in stainless steel materials and pre-forming immediately, and organized experts, owners, supervisors to analyze and discuss the causes and solutions of stainless steel color difference on September 23, 2019, September 24, 2019 and December 26, 2019 successively [4].

\subsection{Three Meetings About Color Difference}

\subsubsection{The First Meeting of Expert Group on Color} Difference on September 23, 2019

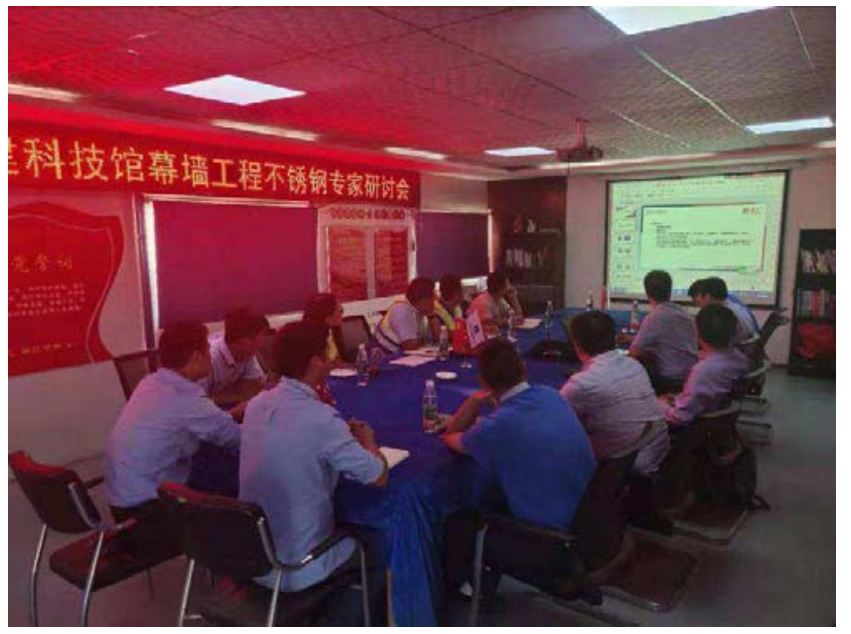

Figure 5. The First Conference photo.

Conclusions:

(1) The stainless steel color difference is common in the stainless steel industry and unavoidable.

(2) It is recommended to place it in natural environment for a long time to make it passivated naturally.

(3) The color difference can be improved by spraying paint on the outer surface of stainless steel.

(4) The amount of stainless steel produced by one furnace cannot meet the needs of this Project. The stainless steel panels in this Project were supplied by three furnaces.

\subsubsection{The Second Meeting of Expert Group on Color Difference on September 24, 2019}

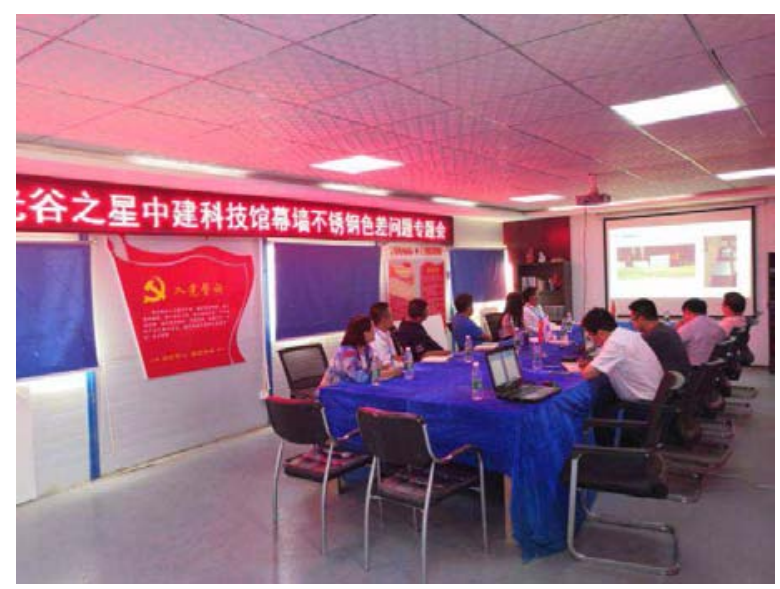

Figure 6. The second Conference photo.

Conclusions:

(1) The single steelmaking capacity of a steel furnace cannot meet the stainless steel needs in this Project. The different batches may have color difference. Even in the same roll of stainless steel plate, there may be a slight color difference, such as head and end of the roll.

(2) The paint coating on outer surface can only solve the surface color difference in stages. Under natural conditions for a long time, such as stainless steel warming due to heat absorption in the daytime and cooling at night, the excessive temperature fluctuation will result in thermal expansion and contraction, poor adhesive force of coating. In rainy and windy weather, the coating may peel off gradually, forming a mottled effect.

(3) The color after natural oxidation will become uniform gradually.

(4) In case of another sandblasting machine is added to meet the production schedule, even though the parameters of sandblasting are adjusted to the same, there will be unexpected color differences in actual operation.

\subsubsection{The Third Meeting of Expert Group on Color Difference on December 26, 2019}

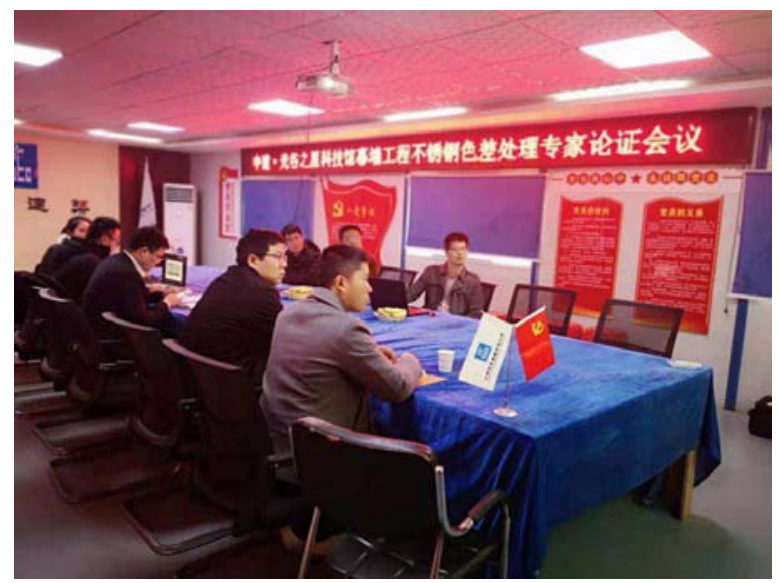

Figure 7. The third Conference photo. 
Conclusions:

(1) The on-site pickling will destroy the specific passive film on stainless steel surface, which is not desirable.

(2) The fluorocarbon coating can improve color difference. However, the specific sense of science and technology of stainless steel will disappear after artificially covering the stainless steel surface [5].

(3) The stainless steel plate is curved by external force. The stress with different directions and intensities will be accumulated inside the material due to different parts and arcs [6]. Stress will produce reflected lights with different colors visible to the human eye under illumination waves.

(4) Stainless steel will naturally fail in the air and form passivation material on the surface. The oxide protection layer will form on the surface naturally with time. The oxide layer will cover the metallic outer surface. The oxide color film will gradually form a uniform color in the layer [7].

(5) It is not recommended to treat the color difference manually, which may cause second color difference.

\subsection{Primary Causes for Color Difference Collected After Three Meetings}

The color difference of stainless steel is a common phenomenon in stainless steel plate industry. The slight color difference will exist in the head and end of same stainless steel coil.

The stainless steel building is in hyperbolic physical shape. There is stress in the curved plate due to plate deformation caused by external force. The stress will emit different colors in the visible light spectrum [8]. There is also a slight color difference in the external surface of a plate due to the different amount of sunlight received by the curved surface in the same plate
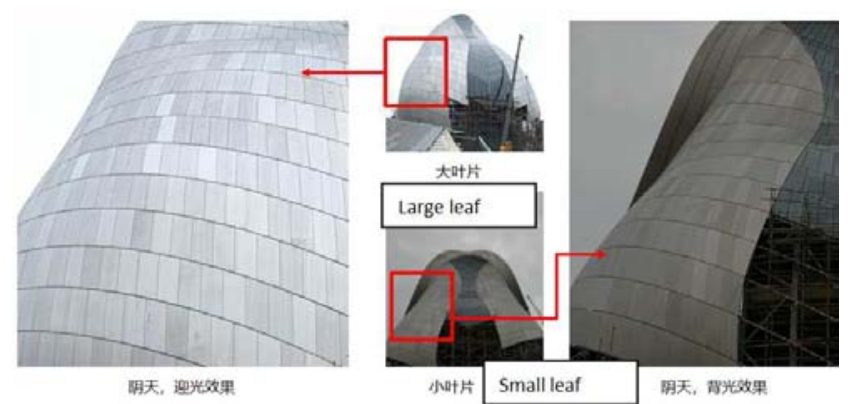

Figure 8. Effect of illuminated face in cloudy day. and effect of shady face in cloudy day.

For hyperboloid sandblasting, the slight changes in sandblasting amount and different angles caused by cambered surface will produce different surface physical preparation and cause color difference under light.

Buildings will have reflected color difference depending on the angle of sunlight. The different light reception degrees are mainly caused by three factors: light angle, viewing angle of human body and plate roughness.
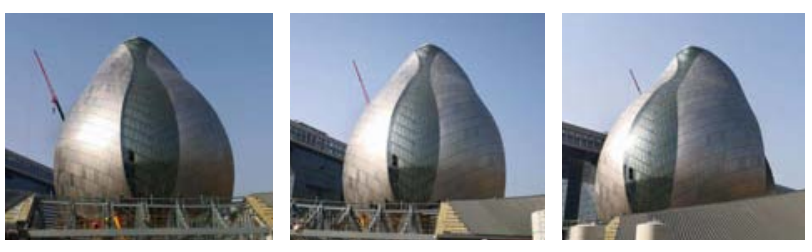

Figure 9. Outside of large leaf with different shooting angles.

\subsection{Three Remedy Tests for Color Difference Immediately}

For the feedback from experts, the Project Department carried out the remedy test for color difference immediately.

\subsubsection{Test 1}

In Test 1 , three imported raw plates with different batches were taken for surface sandblasting preparation with the same parameters to see if there was any color difference.

(1) A total of 6 stainless steel plates with a size of about half the size of on-site standard plate $(1000 \mathrm{~mm} * 1000 \mathrm{~mm})$ were selected. Two stainless steel plates were selected from each of the three batches.

(2) The 6 plates were sandblasted on the same sandblasting machine (old machine), and marked with batch number and sandblasting code clearly.

Conclusion of Test 1 :

(1) The raw material plates of three furnace numbers were marked with Furnace A, Furnace B, Furnace $\mathrm{C}$ and grain direction of plates respectively, and cut into six pieces of $1000 \mathrm{~mm} \times 1000 \mathrm{~mm}$ by laser. The surface films were torn apart to compare whether the raw plates have color difference.
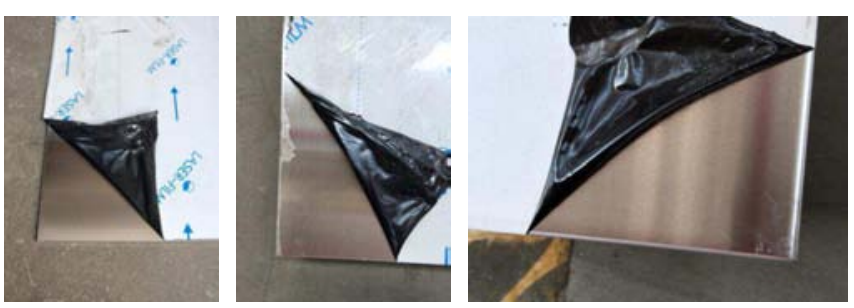

Figure 10. Raw plates of three furnace numbers.

(2) Six plates of different furnace numbers (2 plates for each furnace number) were sandblasted in the direction marked on the sandblasting machine (old machine). According to actual observation, there is no color difference between plates with different furnace numbers using the same sandblasting machine.

\subsubsection{Test 2}

In Test 2, the pickling of stainless steel surface was carried out on site. Samples were tested on the ground to judge the pickling feasibility of stainless steel on site according to the color difference of plates after pickling.

(1) Four stainless steel plates of same batch with a size of half the size of on-site standard plate $(1000 \mathrm{~mm} * 1000 \mathrm{~mm})$ were selected.

(2) Fours plates were polished first. Four plates are equally distributed for two sandblasting machines. Four plates were marked with batch number and sandblasting machine code clearly. 
(3) After sandblasting, one of the plates sandblasted by the two sandblasting machines was selected for pickling respectively.

Conclusion of Test 2: The raw material plate with furnace number of Furnace $\mathrm{C}$ was marked with grain direction of plate and cut into four pieces of $1000 \mathrm{~mm} \times 1000 \mathrm{~mm}$ by laser. Polishing was carried out first. Two pieces of plate were sandblasted in the direction marked on the newly purchased small sandblasting machine (new machine); the other two were sandblasted in the direction marked on the original large sandblasting machine (old machine). According to the observation of samples, it was found that the sandblasting of small sandblasting machine (new machine) is relatively rare with sandblasting lines. The sandblasting color of large sandblasting machine (old machine) is darker. A piece of plate sandblasted by the small sandblasting machine (new machine) and a piece of plate sandblasted by the large sandblasting machine (old machine) were taken for pickling [9].
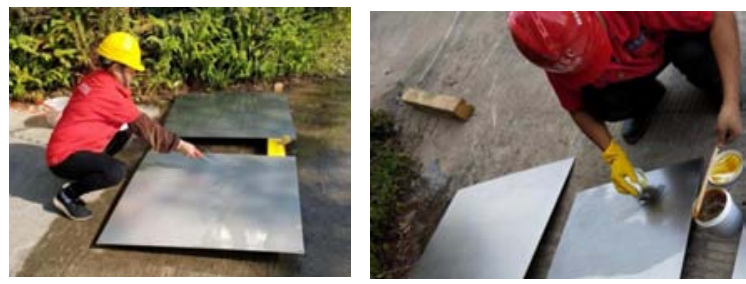

Figure 11. Pickling on outer surface of stainless steel.

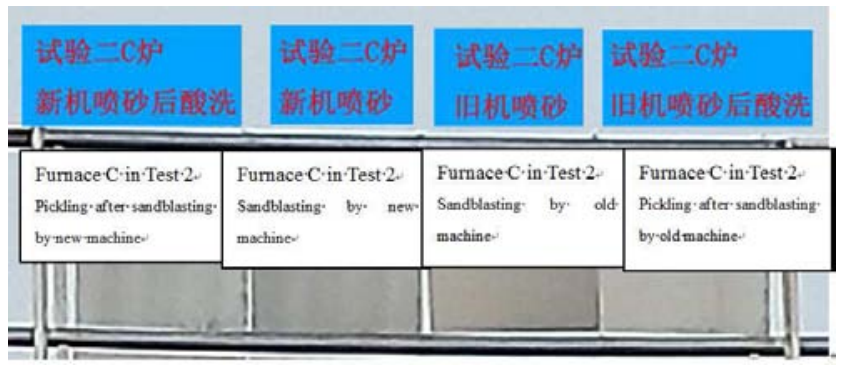

Figure 12. Comparison after pickling.

Discoveries in the test: The acid concentration, acid's duration of stay on the stainless steel surface and the sun's temperature obtained on the stainless steel surface will change the color difference after pickling significantly. The color of stainless steel surface will be inconsistent under slightly different pickling conditions.

\subsubsection{Test 3}

In Test 3, fluorocarbon spraying was carried out on the stainless steel surface by simulating the heights on site. Colors were observed. The samples were sent to the laboratory for adhesion testing.

(1) Two stainless steel plates of same batch with a size of half the size of on-site standard plate $(1000 \mathrm{~mm} * 1000 \mathrm{~mm})$ were selected.

(2) Two plates were sandblasted on the same sandblasting machine (old machine) separately, and marked with codes clearly.

(3) After sandblasting, the two plates were treated with fluorocarbon.
Conclusion of Test 3: The raw material plate with furnace number of Furnace $\mathrm{C}$ was marked with grain direction of plate and cut into two pieces of $1000 \mathrm{~mm} \times 1000 \mathrm{~mm}$ by laser [10].

Two plates were installed after polishing and sandblasting, and sprayed with fluorocarbon paint at heights.
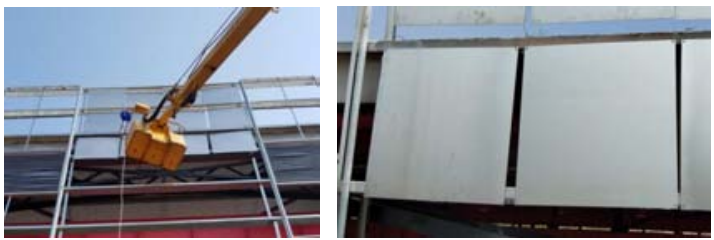

Figure 13. Effect of fluorocarbon spraying on outer surface of stainless steel in high-altitude simulation.

The surface texture can be obviously covered by contrastive paint spraying at close range. According to the observation from a distance, the plate had even color and reflection, without specific metallic luster of stainless steel.

The samples of fluorocarbon spraying on the stainless steel surface were sent to the monitoring station for film coating adhesion testing [11].

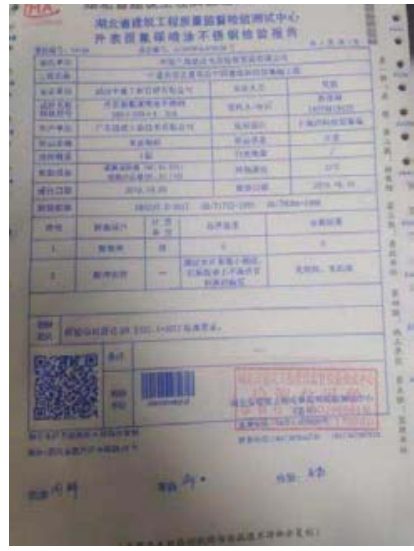

Figure 14. Test report.

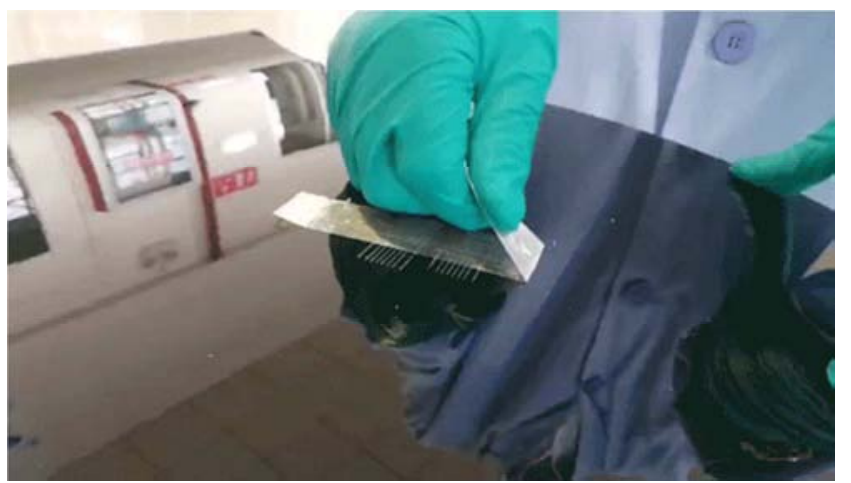

Figure 15. Schematic diagram for adhesion testing of fluorocarbon coating in testing report.

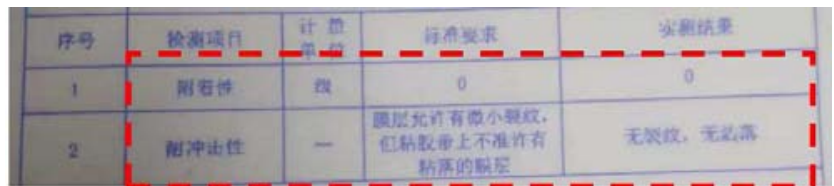

Figure 16. Actual testing results of fluorocarbon coating 
Table 2. Adhesion level.

\begin{tabular}{|c|c|c|}
\hline Classification & Surface appearance of cross cutting area with peeling & \\
\hline 0 & The cutting edge is completely smooth. & No peeling \\
\hline 1 & $\begin{array}{l}\text { There is a little peeling coating at the cut intersection. The affected area of cross cutting area should not be greater than } 5 \% \\
\text { significantly. }\end{array}$ & $\leq 5 \%$ \\
\hline 2 & $\begin{array}{l}\text { There is a little peeling off coating at the cut intersection. The affected area of cross cutting area should not be greater than } \\
5 \% \text { significantly. }\end{array}$ & $5 \%-15 \%$ \\
\hline 3 & $\begin{array}{l}\text { The coating is partially or completely peeled off in large fragments along the cutting edge and/or peeled off at different parts } \\
\text { of grid or peeled off completely. The affected cross cutting area is greater than } 15 \% \text { significantly. It cannot be greater than } \\
35 \% \text { significantly. }\end{array}$ & $15 \%-35 \%$ \\
\hline 4 & $\begin{array}{l}\text { The coating is peeled off in large fragments along the cutting edge and/or peeled off at some parts or peeled off completely. } \\
\text { The affected cross cutting area is greater than } 35 \% \text { significantly. It cannot be greater than } 65 \% \text { significantly. }\end{array}$ & $35 \%-65 \%$ \\
\hline 5 & The peeling degree exceeds Level 4. & I \\
\hline
\end{tabular}

Conclusion: In the surface coating testing, the adhesion is 0 without peeling.

\subsubsection{Summary of Three Tests}

According to the test, pickling on stainless steel surface should be eliminated first. There will be obvious color difference between the surface colors of plates after pickling. The uniform color of stainless steel surface of entire building can only be achieved by immersive pickling, but it cannot be implemented. If large-area pickling is carried out in situ, there is a hidden danger of liquid flow marks, which will cause secondary color difference.

After the stainless steel is sprayed on the ground, the color and film adhesion testing are controllable. However, the high-altitude spraying may not be controlled accurately due to high altitude environment, wind effect, distance of spraying and manual operation. The uniformity of spraying amount per unit area may also cause secondary color difference.

In the case where the above two methods have defects and are not applicable, rash manual control of color difference may enlarge the color difference. The rare metals on the stainless steel surface are oxidized in the natural environment to form a layer of dense oxide film on the stainless steel surface. The color of film covers the stainless steel surface. Therefore, the final color is the color of uniform oxide film formed on the stainless steel surface. With time elapsing, the color of oxide film will tend to be the same gradually and form a uniform color. Although this scheme is relatively passive, it is still a relatively controllable control method for color difference.

\section{Final Opinions on Color Difference Treatment}

The installation of stainless steel took four months. In field observation, it was feel that as time went by, the overall outer surface color of stainless steel was more consistent with reduced color difference compared with the previous period [12].

At night, lights around podium building irradiated the outer surface of stainless steel building with white bright cold light, the stainless steel surface showed obvious color difference.

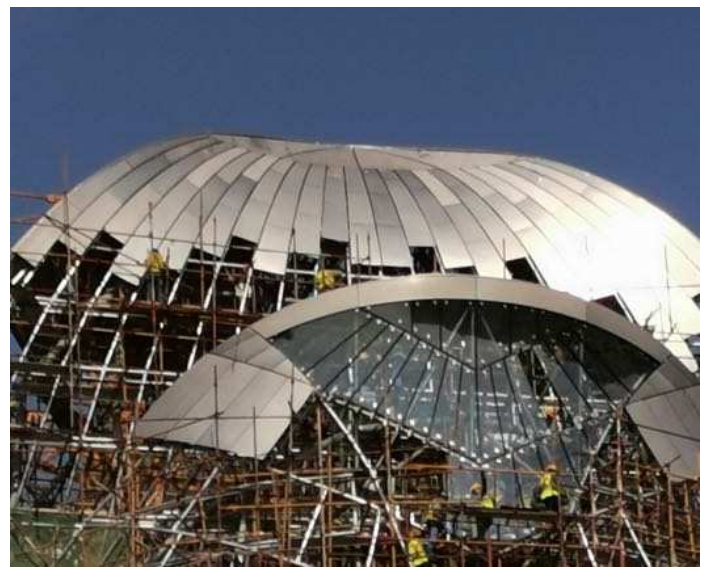

Figure 17. Photo taken on a sunny day on August 29.

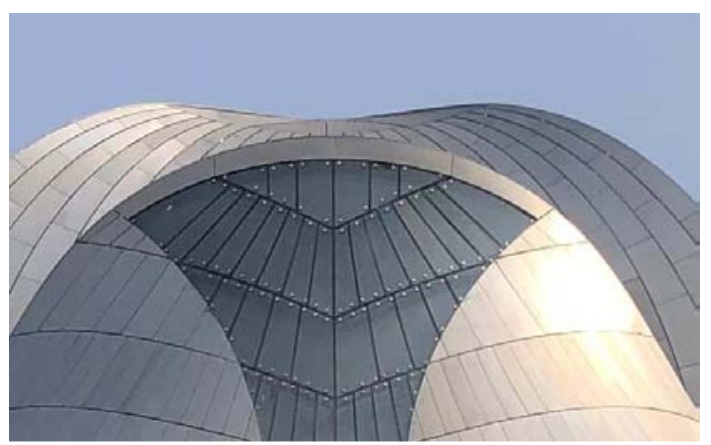

Figure 18. Photo taken on a sunny day on December 22.

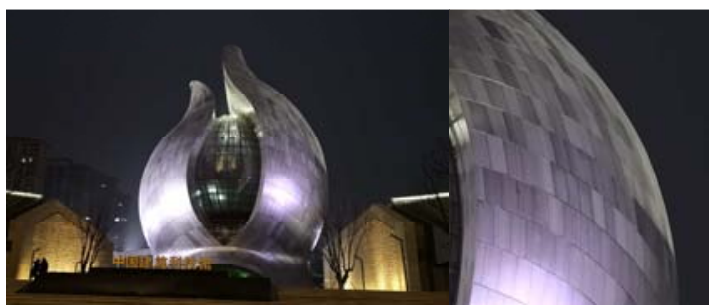

Figure 19. Stainless steel color difference under cold light at night.

It is recommended to replace bright white lights around podium building with spotlights of different colors to irradiate the building exterior to form reflection on stainless steel surface. The building exterior will form a colorful visual effect with dynamic light irradiation, which will be an extraordinary visual appreciation [13]. 


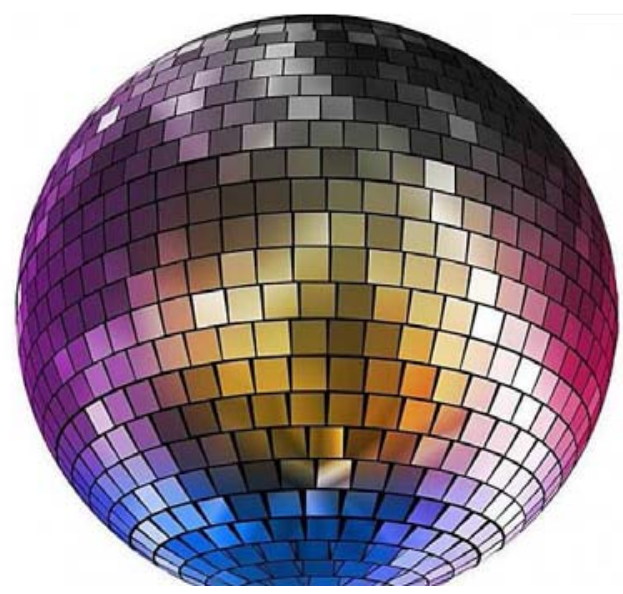

Figure 20. Schematic diagram of laser ball

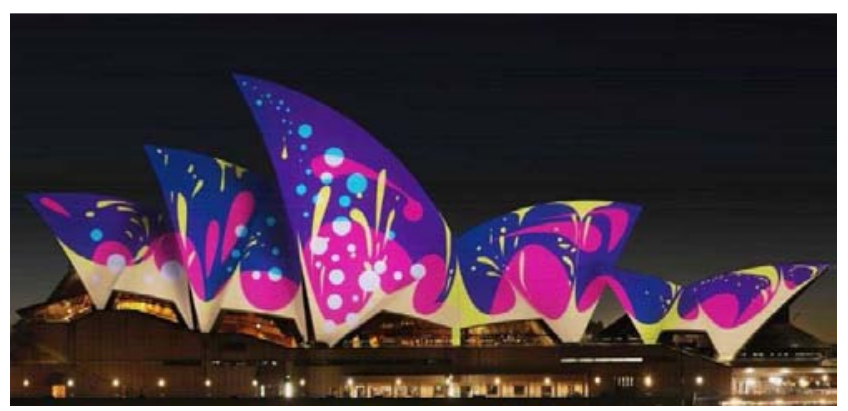

Figure 21. Dazzling 3D light effect of Sydney Opera House - 1 .

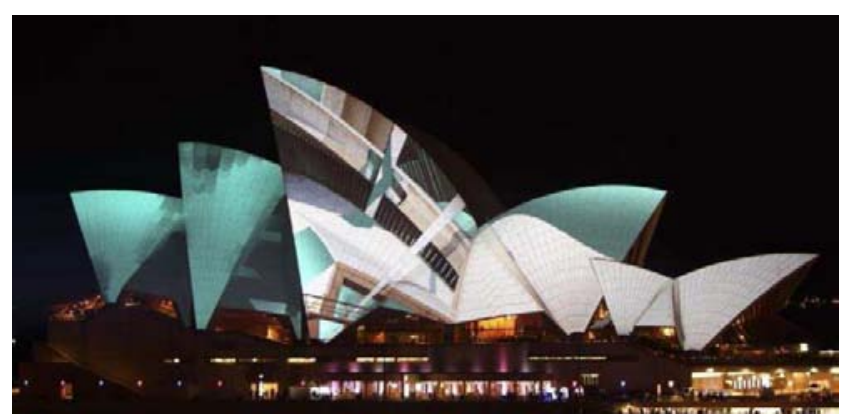

Figure 22. Dazzling 3D light effect of Sydney Opera House - 2.

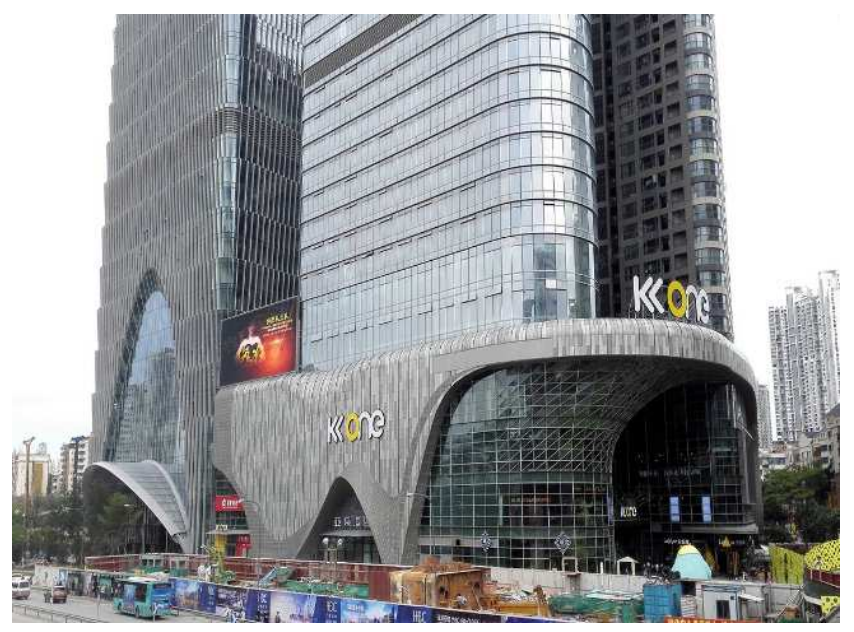

Figure 23. Stainless steel color difference of kkone Shopping Plaza in Shenzhen Binhe Shidai (daytime).

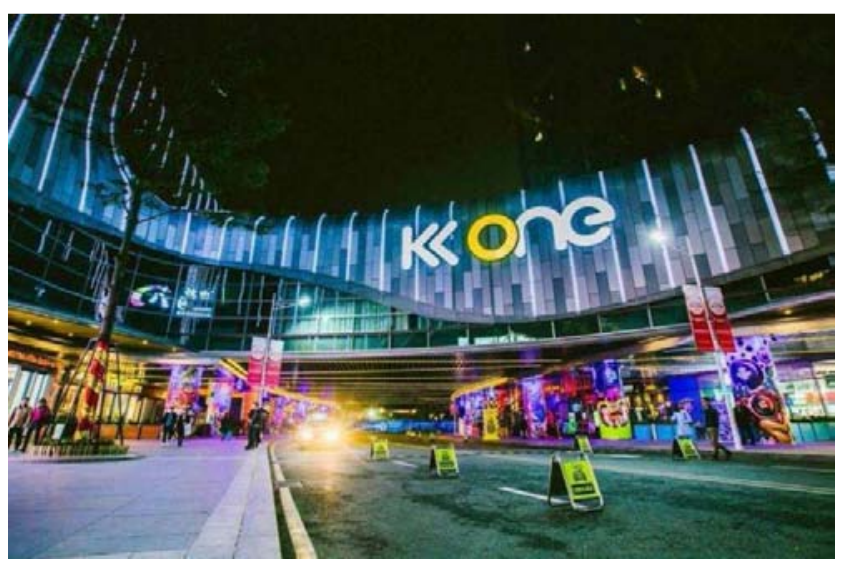

Figure 24. Stainless steel color difference of kkone Shopping Plaza in Shenzhen Binhe Shidai (light effect at night).

\section{Cases of Same Color Difference}

\subsection{Case 1}

Natural oxidation and passivation of stainless steel in Shenzhen Ping An Centre

Take Shenzhen Ping An Centre as an example. Its facade is decorated with stainless steel plates, and there was a similar stainless steel color difference before, as shown below:
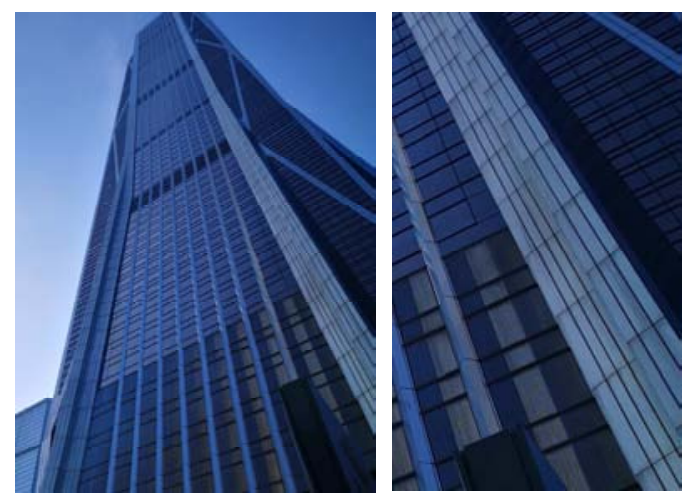

Figure 25. Stainless steel facade of Shenzhen Ping An Centre (white part in the picture).

The stainless steel panels were completely cleaned with passivation cleaner. After the six months of natural passivation, the overall color tended to $95 \%$ consistency.
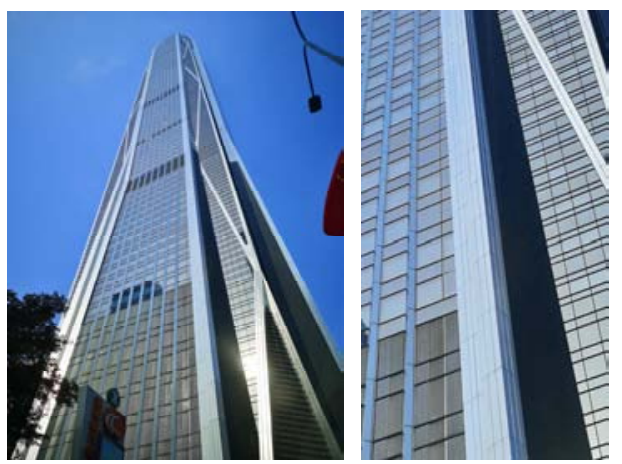

Figure 26. Stainless steel facade of Shenzhen Ping An Centre (effect of six months of natural passivation after cleaning). 


\subsection{Case 2}

Tony Ryan College in Dublin, Ireland

Take the similar curved stainless steel building of Tony Ryan College in Dublin, Ireland as an example. Its stainless steel on the building exterior also has color difference.

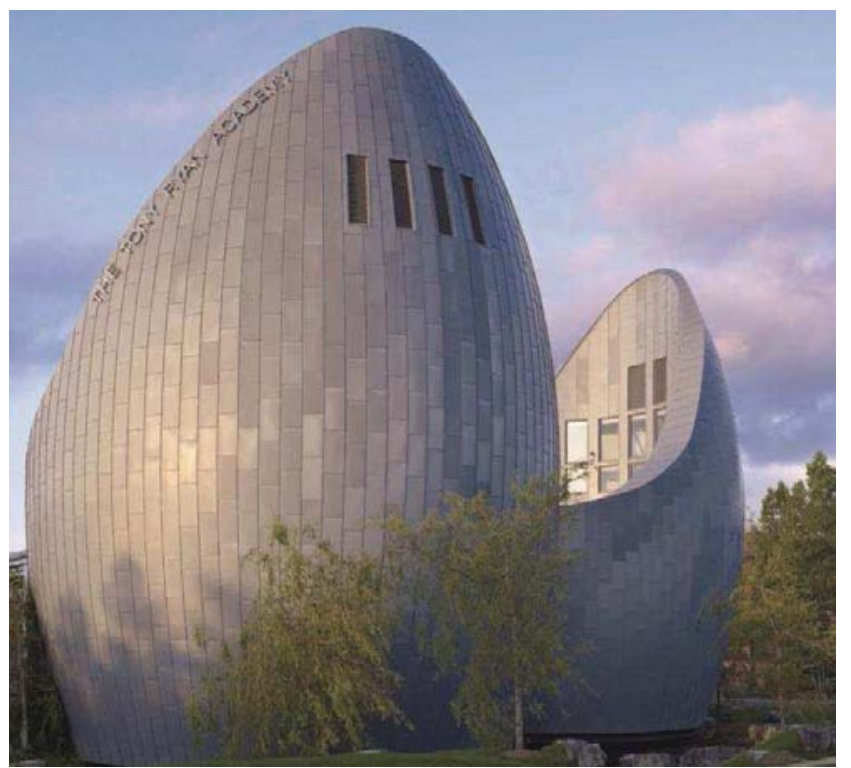

Figure 27. Color difference on stainless steel building exterior of Tony Ryan College in Dublin, Ireland.

The obvious contrast between bright and dark colors of stainless steel on shady face can be seen from the picture. The visual color difference is lighter on illuminated face, with no obvious color difference on convex curved parts. Some plates in concave parts have obvious color difference [14].

\subsection{Case 3}

\section{Shenzhen OCT Harbour}

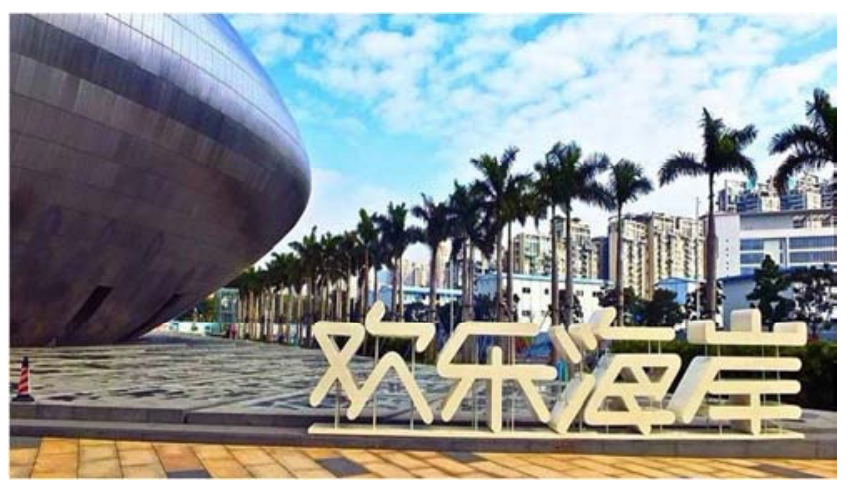

Figure 28. Color difference on stainless steel building exterior of Shenzhen OCT Harbour.

The stainless steel surface of Shenzhen OCT Harbour in above picture has similar color difference.

\subsection{Case Conclusions}

The color difference of stainless steel exists more or less in the famous large-scale buildings at home and abroad.
Opinions generated after 3 expert meetings: It is not recommended to control color difference by manual intervention, which will cause secondary color difference.

Based several test results, it is recommended to passivate stainless steel for 2 to 3 years under natural conditions. With the passage of time, the color will tend to be similar, same and stable.

It is recommended to replace the fixed light irradiation at night with dynamic dazzling lights to improve the technological appearance effect of building under lights and avoid the color difference under cold lights at night skillfully [15].

\section{Postscript}

For stainless steel materials, the secondary processing on the surface should be avoided. Machine or manual processing will bring uncontrollable impacts on the surface color.

It is necessary to purchase plates with same batch and furnace number for raw material of stainless steel. It is necessary to purchase materials with same furnace number and batch for surface material of same part of the building to avoid color difference effectively.

In special-shaped buildings, the reflection light of stainless steel surface is an unavoidable material characteristic. It is necessary to realize that the different amount of light reflected under different angles by materials is a natural scientific phenomenon. It is recommended to select plates with weak reflection light to reduce the diffuse reflection of object itself and reduce the light pollution to man and natural environment caused by buildings.

The experience and summary of stainless steel color difference above may have inspiration for similar color difference on buildings with metal surface. Readers may be able to learn from and gain from it, consider color difference fully before making plan to eliminate color difference in the early stage. When color difference occurs, readers can have correct judgments and psychological expectations about its causes, and have sufficient scientific measures to control or reduce it.

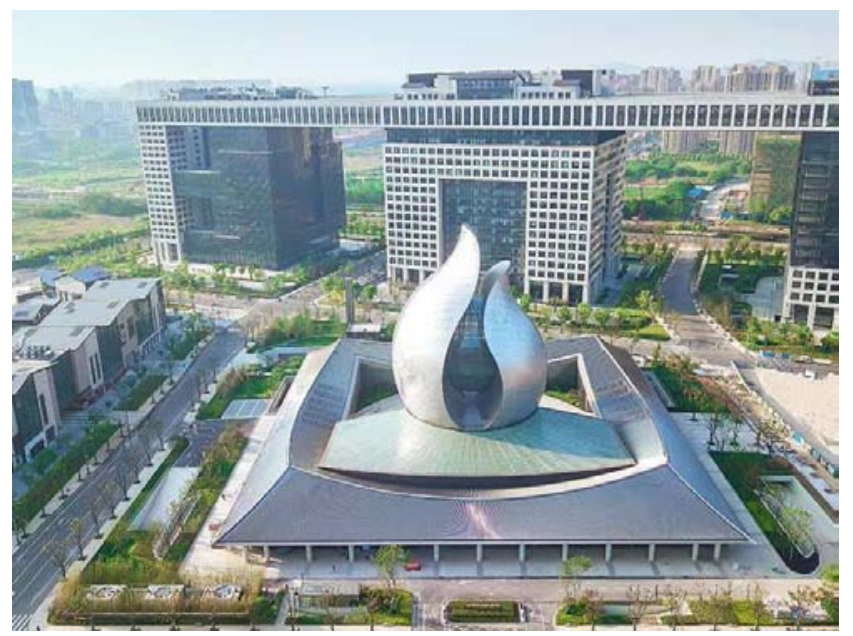

Figure 29. Site photo of Science and Technology Museum - north perspective. 


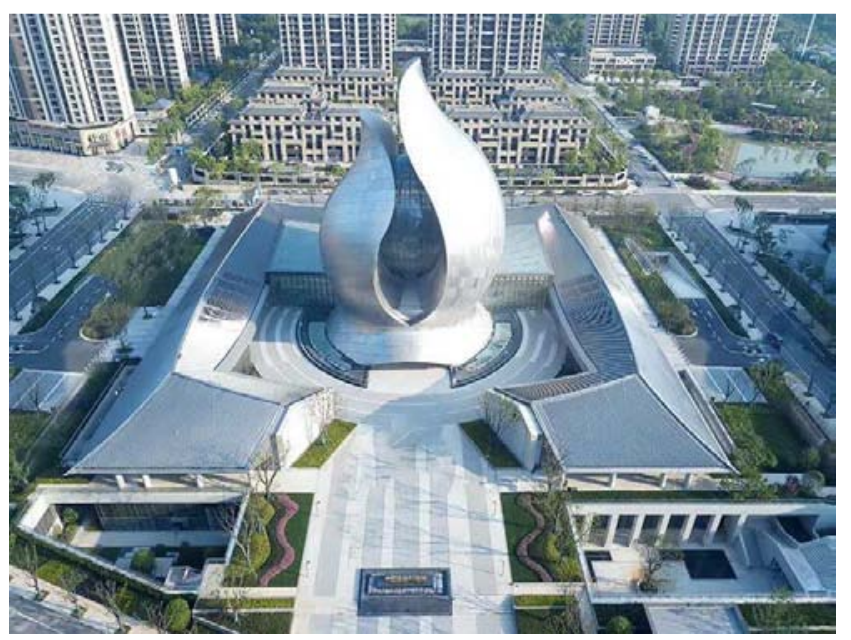

Figure 30. Site photo of Science and Technology Museum - south perspective.

\section{References}

[1] The Market and Technical Potential for Combined Heat and Power in the Commercial/Institutional Sectou. U. S. Department of Energy, Energy Information Administration. 2000.

[2] Construction Technology of Rhombic Folded Aluminum Panel Curtain Wall with Special-shaped Curved Surface [J]. Liang Guideng, Cheng Xiaojian, Mao Wangxing, Wei Xichuan, Tao Lingyan. Construction Technology. 2019 (16).

[3] Discussion on Construction of Hyperbolic Arc-Shaped Pure Aluminum Plate Internal Curtain Wall [J]. Liu Fanmin. Intelligent City. 2018 (07).

[4] Initial Equilibrium Solution Methods for Cable Reinforced Membranes. R. B. Haber, J. EAbel. Comput. Meths. Appl. Mech. Engrg. 2002.
[5] Renew of Form-Finding Method for Tensegrity Structure. A. GTibert, S. [Pellegrino.. 2001.

[6] Analysis on Construction Quality Control and Installation Technology of Glass Curtain Wall [J]. Wang Qiang, Deng Jiqing. Construction Technology. 2019 (S1).

[7] BIM-based Construction Technology of Hyperbolic Aluminum Veneer Curtain Wall [J]. Wu Junfeng, Guangzhou Architecture. 2019 (02).

[8] Application of Plug-and-hang Installation Oof Open Metal Panel Curtain Wall in Engineering. Xu Yu. Engineering Technology [Full Text]. 2016.

[9] Construction Quality Analysis and Supervision Measures of Building Curtain Wall [J]. Wang Hongbing, Hu Aizhen. China Urban Economy. 2010 (11).

[10] NFRC 102, Procedure for Measuring the Steady-State Thermal Transmittance of Fenestration Systems [b] NFRC 102, Procedure for Measuring the Steady-State Thermal Transmittance of Fenestration Systems.

[11] Song, J. H.; Lim, J. H.; Song, S. Y. Evaluation of alternatives for reducing thermal bridges in metal panel curtain wall systems [j] Energy Build., 2016.

[12] ISO 12631, Thermal Performance of Curtain Walling Calculation of Thermal Transmittance [b] ISO 12631, Thermal Performance of Curtain Walling-Calculation of Thermal Transmittance.

[13] A., Serpell; A., Venturi; J., Contreras Lean construction [b] Lean construction, 1995.

[14] J., Mbachu Conceptual framework for the assessment of subcontractors' eligibility and performance in the construction industry [j] Construction Management and Economics, 2008.

[15] J., Dai; P. M., Goodrum; W. F., Maloney Construction craft workers' perceptions of the factors affecting their productivity [j] Journal of Construction Engineering and Management, 2009. 